\title{
REPRESENTAÇÕES DOS ESTUDANTES DE ENFERMAGEM SOBRE SEXUALIDADE: ENTRE ESTEREÓTIPOS E TABUS
}

\author{
REPRESENTATIONS OF NURSING STUDENTS ABOUT SEXUALITY: \\ BETWEEN STEREOTYPES AND TABOOS
}

Trycia Ryane de Freitas Silva ${ }_{(0000-0002-9568-362 x)^{1}}$, Sabrina Emylle Torres Fernandes ${ }_{(0000-0002-}$

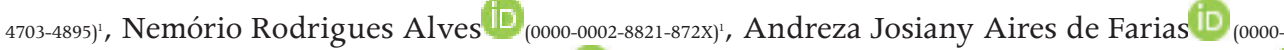
0001-6631-9186)', José Antonio da Silva Júnior ${ }_{(0000-0001-7965-3095)}{ }^{\prime}$, Sheila Milena Pessoa dos Santos $(0000-0001-9396-9192)^{1}$

'Universidade Federal de Campina Grande, Unidade Acadêmica de Enfermagem, Graduação em Enfermagem, Campina Grande, Paraíba, Brasil.

$<$ trycia_ryane@hotmail.com>

Resumo Considerando a sexualidade como parte fundamental da vida humana, esse estudo buscou compreender como os estudantes de enfermagem representam a sexualidade. Optou-se por estudo com delineamento qualitativo, ancorado na teoria das Representações Sociais. A população do estudo foi composta por acadêmicos do curso de graduação em uma instituição pública. A coleta de dados foi realizada por meio da técnica de grupo focal, orientado por um roteiro. A análise foi realizada como auxílio do IRaMuTeQ versão 0.7 alpha 2 e embasada na Análise de Conteúdo. A sexualidade foi representada como algo a ser velado no âmbito familiar e escolar. Apesar da formação ter se revelado como um fator que contribuiu na mudança de concepção sobre a sexualidade, sentimentos como vergonha e timidez se fizeram presentes durante as práticas dos estudantes, constatando que as representações se ancoram em estereótipos e tabus. Assim, é visível a necessidade de mais espaços de discussão no meio acadêmico e na sociedade, de forma que não se limite à teoria, mas que compreenda também a prática.

Palavras-chave sexualidade; educação em enfermagem; saúde sexual; representações sociais.
Abstract Considering sexuality as a fundamental part of human life, the present study had the goal of understanding how Nursing students represent sexuality. We chose to make a qualitative research based on the Social Representation theory. The study sample was composed of undergraduate Nursing students enrolled in a public institution. The data collection was performed with the aid of the IRaMuTeQ software, version 0.7 alpha 2, and it was based on Content Analysis. Sexuality was represented as something that should remain hidden both in the context of school and within the family. Even though their training was a factor that contributed to their change in conception about sexuality, feelings such as shame and shyness were present during the practices of the students, which verified that the representations are based on stereotypes and taboos. Thus, there is a visible need for more spaces for discussions within the university and within society, but discussions that understand the practice, and are not limited to theory.

Keywords sexuality; education in nursing; sexual health; social representations. 


\section{Introdução}

A sexualidade é uma dimensão fundamental na vida humana, portanto não pode ser separada de outros aspectos da vida, pois influencia pensamentos, sentimentos, ações e interações (World Health Organization, 2017).

Constituindo-se como construção histórica, produzida na cultura, carregada de instabilidade e multiplicidade, as formas de vivenciar a sexualidade precisam ser compreendidas em uma dimensão inerente à sociedade e à cultura (Louro, 2007).

A construção da sexualidade é resultado das diversas e variadas socializações que uma pessoa experimenta em sua vida: família, escola, acesso a distintos meios de comunicação, redes de amizade e vizinhança (Heilborn, 2006).

Do ponto de vista sociocultural, a sexualidade está situada na esfera dos interditos e, sendo assim, sua abordagem é muitas vezes evitada. Por conseguinte, ela é vista como um assunto sensível e delicado, pertencente ao âmbito privado (Ferreira et. al., 2015).

O estudo realizado por Sehnem et al. (2014) mostrou que a sexualidade, embora esteja presente em todos os âmbitos da vida, ainda é silenciada no cuidado de enfermagem. Ao ser tratada como tabu, reproduz silêncios, inseguranças e constrangimentos que podem perpassar a vivência da temática no cuidado.

Deste modo, a forma como o profissional compreende a sexualidade reflete sobre os cuidados em saúde, pois em estudo realizado por Sehnem et al. (2013b), evidenciou-se que a sexualidade tem sido vivenciada, no cuidado de enfermagem, relacionada a sentimentos como nervosismo, insegurança, angústia e constrangimento.

Como a temática da sexualidade humana geralmente é pouco abordada, a construção do conhecimento se dá por meio de estrutura pedagógica tradicional, na qual o cuidado de enfermagem é prestado de modo mecânico, tecnicista e acrítico (Ziliotto e Marcolan, 2013).

Ao reproduzir o modelo biomédico, os profissionais se preocupam com o cuidado voltado à dimensão biológica, restrito ao desenvolvimento de práticas com foco na cura, mediado por técnicas que não valorizam as subjetividades, fragilizando o cuidado (Ferreira et al., 2015).

No percurso formativo, nota-se a existência de uma lacuna no ensino, no que se refere à formação acadêmica do estudante para lidar com questões voltadas à sexualidade no cuidado de enfermagem. Isso ocorre devido à inexistência de ambiente que incentive ao estudante revelar suas dificuldades e sentimentos em relação à sexualidade no cuidado, mantendo-a silenciada (Sehnem et al., 2014).

Atualmente, ao considerar essas questões no processo de formação do enfermeiro, deve-se investir na ruptura dos estereótipos e tabus que envolvem 
a sexualidade. Portanto, espera-se que o estudante aprenda sobre conteúdos e estratégias de abordagens da sexualidade nos cuidados em saúde, sendo preciso romper com o silêncio em torno da temática dentro da formação, visto que a sexualidade é parte da integralidade humana (Costa e Coelho, 2011). Sendo assim, defende-se o argumento de que o fazer saúde remete a uma possibilidade de conexões entre discursos e práticas.

Construir outros modos de fazer saúde é algo que se mantém em tensão constante, já que estamos todos imersos em paradigmas que sustentam as nossas práticas (Chiapinotto et al., 2007).

Partindo do pressuposto de que o profissional de saúde é um agente com potencial para fazer cumprir o processo terapêutico em sua integralidade, é de grande relevância considerar a maneira que a formação influencia suas concepções no tocante à sexualidade humana (Silveira et al., 2014).

Desse modo, este estudo buscou compreender as representações de estudantes de Enfermagem sobre sexualidade.

\section{Representações construídas nas vivências dos estudantes de enfermagem}

Com o propósito de alcançar o objetivo proposto, optou-se por estudo com delineamento qualitativo, ancorado na teoria das Representações Sociais (RSs). Sendo assim, o estudo permite uma melhor compreensão do problema, ao explorar um conceito ou um fenômeno. A investigação qualitativa emprega diversas alegações de conhecimento, táticas de averiguação, métodos de coleta e análise de dados. Este tipo de pesquisa está focado na percepção e experiência dos participantes e, consequentemente, da maneira como eles compreendem a realidade (Creswell, 2007).

A teoria das RSs confere elevado grau interpretativo ao objeto de estudo, promovendo a compreensão dos sistemas de significação que são produzidos e partilhados por um grupo (Moraes et al., 2013). As RSs influenciam nossa relação com o mundo e com as outras pessoas, orientando e organizando o comportamento e as comunicações sociais.

A população aqui estudada compreende os discentes do curso de Graduação em Enfermagem da Universidade Federal de Campina Grande, dos quais, na época do estudo, representavam o total de 173 discentes matriculados e ativos e 14 alunos inativos.

Para composição da amostra foi usada a amostragem não probabilística do tipo intencional.

A coleta de dados foi realizada por meio da técnica de grupo focal, o que permitiu colher informações que proporcionaram a compreensão de percepções, crenças e atitudes sobre o tema (Trad, 2009).

O grupo focal é caracterizado pela presença do moderador, que se torna um facilitador do desenvolvimento da discussão, e sua ênfase baseia-se nos 
processos psicossociais emergentes. Deste modo, a unidade de análise é o próprio grupo. As representações sociais traçadas nos movimentos do grupo têm, nos grupos focais, um importante utensílio investigativo no que se diz respeito à oportunidade de captar tais representações, seus conteúdos e movimentos constitutivos, o que possibilita especialmente investigações sobre as características que compõem sua sociogênese. Durante um encontro de grupo focal, é possível ressaltar os movimentos grupais essenciais na constituição das RSs (Nóbrega, Andrade e Melo, 2016).

Os participantes desta pesquisa foram organizados em três grupos focais (GFs): GFl com nove integrantes discentes do $2^{\circ}$ período, GF2 com oito discentes do $6^{\circ}$ período e GF3 com treze integrantes discentes do $9^{\circ}$ período, sendo ao todo 30 discentes. Compuseram cada turma, respectivamente, 16, 12 e 21 estudantes. Dessa forma, foi realizado um encontro com cada grupo separadamente. Não houve recusas quanto à participação, contudo, alguns discentes não compareceram e justificaram sua ausência devido a outros compromissos. Ao final das atividades, foi contabilizado 19 faltantes.

Os participantes do $2^{\circ}$ período foram escolhidos por estarem iniciando a formação acadêmica. Os participantes do $6^{\circ}$ período foram selecionados por estarem com mais de 50\% do curso concluído. Por fim, os participantes do $9^{\circ}$ período foram eleitos para a pesquisa por estarem cursando o penúltimo período do curso, realizando estágio supervisionado I, tendo passado por $90 \%$ do curso.

Os participantes tiveram como critérios de inclusão: ter 18 anos ou mais, não houve limitação por deficiência, religião ou renda, devendo estar matriculados e ativos em um dos três períodos do curso citado. Os critérios de exclusão foram: participantes com idade abaixo de 18 anos e alunos inativos no curso.

Os participantes foram convidados previamente por meio eletrônico, de modo que foram informados sobre a data, hora e cronograma da reunião que incluía momento de credenciamento, lanche, início da atividade e encerramento.

As coletas foram realizadas nos dia 17 e 18 de agosto de 2017. Foi realizado planejamento passo a passo da entrevista e construído um roteiro para a execução dos grupos focais. Decidiu-se que a orientadora do projeto não estaria presente no desenvolvimento dos grupos devido ao risco de inibição dos discentes entrevistados.

$\mathrm{O}$ ambiente escolhido para a pesquisa foi uma sala de aula que teve como características principais: boa iluminação e ventilação; espaço adequado para comportar os participantes e longe de ruídos externos. Para proporcionar um ambiente confortável e motivador foram usados: música ambiente, tapetes, almofadas e lanche. Tais itens tiveram o objetivo de tornar o ambiente mais agradável e descontraído. 
A coleta destes grupos focais contou com a presença de duas moderadoras graduandas e duas observadoras, sendo a função das observadoras, captar a expressão dos participantes durante o grupo focal sem se manifestarem.

De acordo com Trad (2009), o moderador deve possuir condição substancial de conhecimento do tema em discussão. Ele deve ser sensível e ter cautela para dirigir o grupo, mantendo-os no foco sobre a importância do estudo, enfatizando aos participantes a possibilidade de expressar-se espontaneamente.

Tratando-se de temática complexa, foi usada uma frase disparadora do estudo e imagens como estratégias que favorecessem a espontaneidade dos participantes durante a realização dos grupos focais. A frase disparadora formulada pelos pesquisadores permitiu reflexões sobre a sexualidade: "Comente sobre a sexualidade em sua vivência". Além disso, foram utilizadas frases que suscitaram a discussão em torno dos sentimentos, modos de expressar e abordar a sexualidade. A construção dessas frases ocorreu com base em estudos desenvolvidos por Ressel (2003), Cesnik (2013), Saunamäki e Engström (2014).

Já as imagens foram extraídas aleatoriamente do Google Imagens. Foram disponibilizadas para os participantes aproximadamente 50 imagens que foram dispostas no meio dos círculos dos participantes.

De acordo com Bernardes et al. (2014), as imagens se distinguem por possibilitar reflexões e discussões sobre temáticas relevantes, apresentandose como linguagem não verbal. Estes autores ainda afirmam que as imagens informam e comunicam, transformando-se em discurso e tornando-se aparente pela interpretação, produto do efeito que se dá entre imagem e a observação do participante.

Com a finalidade de registrar e armazenar as informações obtidas nos grupos focais, foi solicitada autorização para a uso de um gravador de mp3 durante o encontro com os participantes. Além disso, para a coleta de dados, foi usado um diário de campo que teve como função descrever as situações e a dinâmica dos participantes durante o grupo focal.

Com auxílio das imagens relacionadas à sexualidade e das questões disparadoras, o grupo focal foi realizado sem intercorrências. Os participantes sentiram-se abertos a expressar emoções, sentimentos e percepções sobre a sexualidade, relatar experiências pessoais durante a formação e explicitar opiniões. Cada grupo teve duração média de duas horas.

O material coletado foi analisado por meio da técnica de Análise de Conteúdo que pode ser compreendido como um conjunto de técnicas empregadas na análise dos dados qualitativos. Para Bardin (2006), a Análise de Conteúdo deve ser embasada no rigor metodológico como forma de não fugir do objetivo.

Com o intuito de auxiliar a interpretação dos dados, foi usado o software IRaMuTeQ versão 0.7 Alpha 2, que viabiliza diferentes tipos de análise de dados textuais, organizando a distribuição do vocabulário de forma compreensível e visualmente clara com representações gráficas baseadas nas análises 
efetuadas. Desse modo, seu uso facilitou a interpretação das entrevistas e contribuiu na elaboração dos resultados da pesquisa (Camargo e Justo, 2013).

As declarações foram categorizadas em: 'Aprendizado na infância e adolescência'; 'Tabus e estereótipos na formação'; 'Representações sobre sexualidade', agrupadas em corpus textuais e inseridas no Software IRaMuTeQ, no qual foram geradas imagens por meio da Análise de Similitude que puderam ser interpretadas.

O risco referente a esta pesquisa foi o desconforto ao falar de intimidade, sendo minimizado ao permitir que o participante ficasse em silêncio e desistisse de participar da pesquisa a qualquer tempo. Além disso, foi preservado sigilo em todas as fases da pesquisa.

Além do conhecimento voltado às concepções e vivências sobre a sexualidade dos discentes de enfermagem, fruto da divulgação dos resultados obtidos, o participante não teve benefício direto ao participar desta pesquisa.

$\mathrm{O}$ estudo atendeu aos preceitos da pesquisa com seres humanos, estabelecidos pela Resolução 466/12 e pela Norma operacional 001/2013, ambas do Conselho Nacional de Saúde, sendo aprovado no Comitê de Ética do Hospital Universitário Alcides Carneiro (HUAC/UFCG) com número do parecer 2.163.408 em 07 de julho de 2017. Sua realização se deu com a assinatura do termo de consentimento livre e esclarecido.

\section{Resultados e Discussão}

A maioria dos entrevistados era do sexo feminino (24), isso se justifica no fato de que a enfermagem é uma profissão predominantemente feminina. Em relação à idade, 17 estudantes tinham entre 18 e 21 anos e 13, entre 22 e 26 anos. A maioria dos estudantes (21) era da religião católica; sete, protestantes e dois não possuíam religião. A maioria deles (17) não possuía parceria sexual no momento da pesquisa.

Para o GF1, o tema sexualidade até então não havia sido abordado em sala de aula. Para os GF2 e GF3, a disciplina de Saúde do Idoso abordou a sexualidade com foco na condição da pessoa idosa de forma sucinta. No decurso dos dois últimos GF, ficou evidenciado que a disciplina que mais abordou a sexualidade foi a de Saúde da Mulher.

\section{Categoria 1 Aprendizado na infância e na adolescência}

As representações sobre sexualidade foram relacionadas ao aprendizado e experiências na infância e na adolescência. Neste aprendizado o contexto foi predominantemente familiar e escolar. 
Análise de similitude: Aprendizado na infância e na adolescência

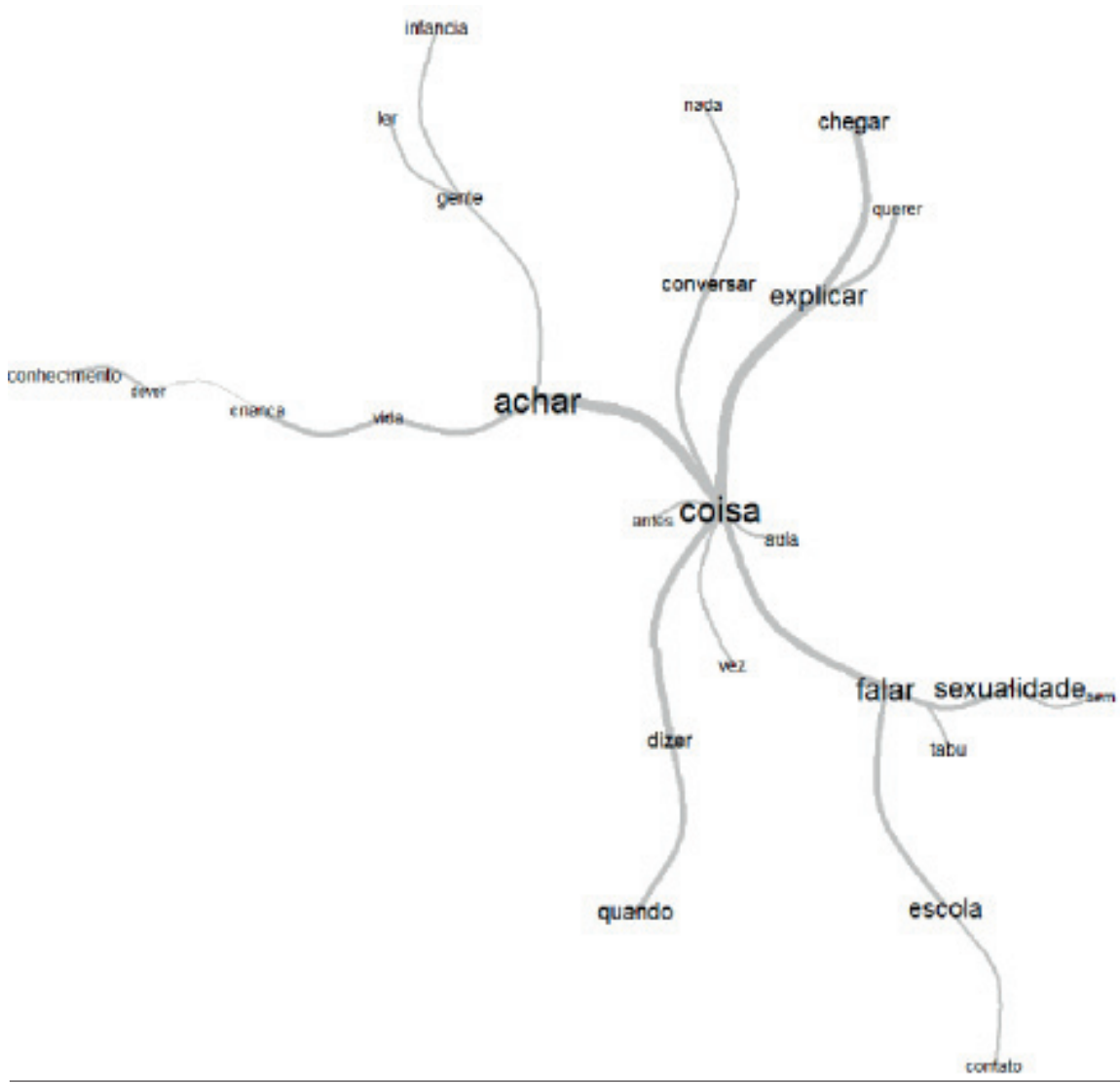

Fonte: Os autores.

Observa-se que, ao se analisar o tema, a palavra 'escola' surge. Durante a abordagem do assunto, a maioria dos entrevistados evidenciou que o ambiente escolar representou um local de pouca ou nenhuma troca de conhecimento sobre sexualidade, atendo-se à biologia e descartando os aspectos psicossociais.

O enfoque no aspecto biológico da sexualidade na adolescência é indício do silêncio em torno do tema. A visão fragmentada alude ao modelo biomédico, sendo desprezados os aspectos psicológicos, sociais e culturais (Queirós et al., 2016).

Alguns fatores, como falta de diálogo no seio familiar, ausência de orientações sobre educação sexual nas escolas e a falta de acesso aos serviços de saúde, influenciam na adoção de práticas sexuais inseguras entre os adolescentes (Albuquerque et al., 2015). 
Às vezes numa aula de biologia, explicava sobre DST e essas coisas (GF1).

Eu acho que eu fazia a quinta série, veio o pessoal da unidade de saúde falar sobre sexualidade na escola. Eu tinha onze anos, então abaixo de quinze não deixaram ninguém ficar na sala de aula, excluíram todo mundo. E os professores, que deveriam ser incentivadores do conhecimento, agiram assim (GF3).

Na minha escola esse assunto não era debatido. Era uma escola de freiras (GF2).

Ao longo dos relatos, nota-se que na família o tema sexualidade era tabu, evitava-se a discussão e tinha que ser interpretado através de tons de fala e com enfoque no aspecto biologicista.

A única vez que meu pai falou sobre isso, quando eu estava para vir embora, eu tive que interpretar o que ele disse. Ele disse assim, tome cuidado viu. Eu disse certo. Foi o tom, pelo jeito que ele falou. Eu percebi que ele estava falando em relação a sexo, essas coisas. Mas foi o único momento que foi falado lá (GF2).

Minha mãe nunca conversou nada sobre isso comigo. A única coisa que ela disse, quando eu tinha 15, 16 anos, foi que quando eu tivesse um namorado iria me levar em um ginecologista para me dar remédio. Ela não conversava nada (GF1).

Devido aos entraves relacionados ao tema, a sexualidade infantil deve ser pensada na perspectiva de educação para a saúde, visto que é parte da integralidade humana (Silva, Schmitz e Menezes, 2017).

Dessa forma, o conhecimento sobre o tema durante a infância e a adolescência era resultado da troca de experiência entre amigos e colegas, com o risco de troca de informações incorretas.

Eu conheci mais sobre esse assunto com os amigos. Que às vezes nem falavam as coisas certas (GF2).

Na escola tinha, tanto escutava dos amigos, contava experiências (GFl).

Observa-se, com base nos trechos, que durante a infância o aprendizado sobre a sexualidade era restrito. De acordo com Hora e Schindhelm (2015), isso ocorre porque no senso comum a infância é relacionada à ingenuidade. Dessa forma, o tabu da sexualidade e da infância se traduz em dois aspectos que não devem se entrelaçar, representando algo negativo a ser combatido.

Para Costa e Coelho (2013), o aprendizado e as experiências vividas relacionadas à sexualidade exercem influência sobre o modo de agir e atitudes 
dos profissionais envolvidos no cuidado. Desse modo, ao ingressar na universidade, o discente possui uma visão limitada sobre a sexualidade.

\section{Categoria 2 Estereótipos e tabus na formação}

Nesta categoria, as representações dos discentes mostram-se relacionadas a estereótipos e tabus.

\section{Figura 2}

Análise de similitude: Estereótipos e tabus na formação

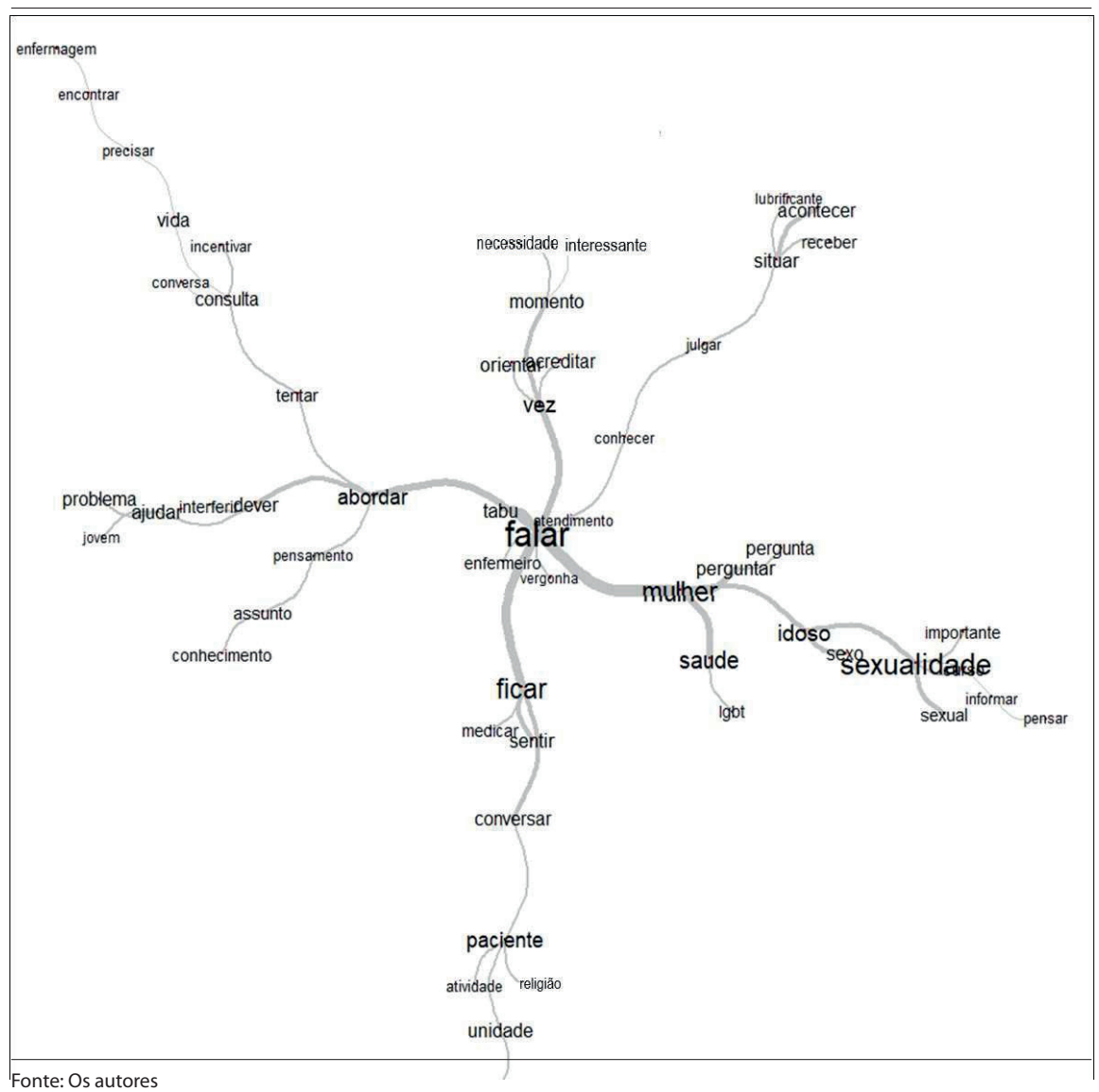

Ao analisar o tema estereótipo e tabu na formação, o termo 'vergonha' surge, reafirmando a representação da sexualidade como algo a ser escondido e velado. As declarações expressam sentimentos como constrangimento, timidez e vergonha relatados pelos estudantes, quando se referem à abordagem do assunto em suas práticas, como a seguir: 
Nos estágios de Saúde da Mulher, nós abordamos a sexualidade do outro, quando a gente pergunta sobre a quantidade de relações sexuais, se tem parceiro. É aquela coisa bem tímida (GF2).

A vergonha, normalmente associada a este tema, surge não só pelas crenças e ideias individuais, mas também pela construção histórica social que tem transformado a sexualidade em algo traumático (Pancake, 2012).

Os trechos a seguir trazem a percepção do discente diante da religião, da timidez e do retraimento das mulheres que eram atendidas nas atividades práticas das disciplinas, transformando tais juízos em barreira para o questionamento sobre a sexualidade:

A gente sentiu mesmo dificuldade de perguntar, por conta da religião de algumas. Elas não queriam ficar expondo, e pela idade também, por serem mais velhas. Tem todo aquele tabu de ficar falando sobre isso (GF2).

Algumas religiões veem a sexualidade segundo uma perspectiva negativa, que deve ser tolerada apenas pela necessidade da procriação (Busin, 2011). Para a maioria dos estudantes religiosos, a sua crença não interfere em sua visão sobre a sexualidade, contudo, o fato da paciente ter religião apresentase como um entrave ao questionamento sobre a sexualidade. A timidez ou retraimento das mulheres em atendimento também se mostra como uma dificuldade. Para Sehnem et al. (2013a) as dificuldades ao se debater sobre o tema, seja em relação ao discente ou ao paciente, revelam marcas deixadas durante a formação da sexualidade.

A presença do termo 'julgar' mostra a representação que o discente possui sobre os espaços de saúde ao se tratar da sexualidade.

Eu fui para perguntar por uma amiga minha, que estava com vergonha, sobre o teste rápido para doenças sexualmente transmissíveis. Então a enfermeira olhou para a minha cara e fez: Mas mulher! Fizesse sem proteção, foi? Tanta camisinha aí sendo distribuída, como é que você faz sem proteção? Aí eu falei: não, não é para mim não (GF2).

Esse relato torna explícito que, na perspectiva do discente, os espaços e os profissionais de saúde mantêm barreiras no que se refere à abordagem do tema. Dessa forma, os entrevistados refletiram sobre a necessidade de mudança de um ambiente que se isenta do papel de informar para um espaço de rompimento de tabus e troca de conhecimento.

Garcia e Lisboa (2012) afirmam que, dentre as habilidades que o enfermeiro deve possuir para lidar com os pacientes, deve-se somar a de não julgar e não agir com preconceito. 
O preconceito em torno do tema dificulta a abordagem nas ações de assistência à saúde (Ferreira et al., 2015) e leva a dificuldades no cuidado relacionadas às funções que os espaços de saúde devem cumprir no tocante à sexualidade. As palavras 'orientar', 'ajudar', 'informar' sugerem a representação dos discentes sobre o papel que os espaços de saúde devem cumprir de serem locais de troca de conhecimentos.

Eu peguei essa imagem retratando a importância da orientação. Muitas vezes os pacientes sofrem por coisas que a gente poderia orientar e poderia ser evitado. Com atividade educativa, poderia ser explicado o que é sexualidade. Se a gente não chegar e explicar podem achar que determinadas coisas são normais sem ser (GF3).

Alencar et al. (2014) afirmam que, diante do processo de construção da sexualidade, o enfermeiro como educador tem papel de destaque, visto que pode inserir nos espaços de saúde atividades relativas à educação sexual.

Ao se deparar com a realidade do processo de trabalho nos serviços de saúde, relatado pelos participantes, é importante o questionamento acerca da formação que os estudantes recebem na universidade. Assim, no que toca à abordagem da sexualidade na universidade, foi relatado que poucas disciplinas abordam e poucos momentos de conhecimento e orientação sobre a temática são vivenciados.

E aqui na universidade mesmo, não é toda disciplina que fala. A gente não viu isso em semiologia. Viu em saúde da mulher e em saúde do idoso (GF2).

Eu nunca vi um atendimento voltado pra uma pessoa transgênero, transexual (GF3).

Eu acho que o único momento em que foi falado, assim diretamente sobre isso, foi em saúde coletiva que foi um seminário sobre LGBT, mas depois disso nada foi falado. E tem poucas discussões até extra sala de aula (GF2).

Acho que esse assunto deveria ser mais abordado, justamente para ajudar a quebrar esses tabus (GFl).

Ao se tratar da abordagem à sexualidade do outro, o GFl não apresentou experiências; no entanto, os discentes acreditam que o sentimento que prevalece é o constrangimento, e o grupo apontou a necessidade de conhecer o paciente para saber a melhor forma de mencionar o tema. O sentimento de receio e timidez foi mencionado por integrantes do GF2 e do GF3, todavia, ressaltam compreender a importância de tal abordagem.

Os GF2 e GF3 acreditam que a universidade não lhes preparou suficientemente para abordar a sexualidade. O GF3 salientou ainda a importância da busca de conhecimento em outros espaços para maior familiaridade com o tema. 
De um modo geral, observa-se, através dos depoimentos, que este tema é insuficientemente abordado dentro da universidade, contribuindo para o despreparo dos estudantes e sentimentos de timidez ao lidar com a sexualidade do outro. Como futuros profissionais, tal despreparo propicia o fortalecimento de barreiras nos espaços de saúde (Ziliotto e Marcolan, 2013).

Assim, percebe-se que sexualidade precisa ser compreendida como parte da integralidade, para que seja então cada vez mais inserida nos currículos de formação do enfermeiro (Sehnem et al. 2013a).

\section{Categoria 3 Representações sobre sexualidade}

Essa categoria aborda as representações que os discentes possuem sobre o conceito de sexualidade e as diferenças constatadas entre os GFs.

As percepções sobre a sexualidade não se diferenciaram em torno da idade e parceria sexual, tampouco pela religião, mas sim pelo período em que se encontrava cada grupo.

Figura 3

Análise de similitude: representações de sexualidade

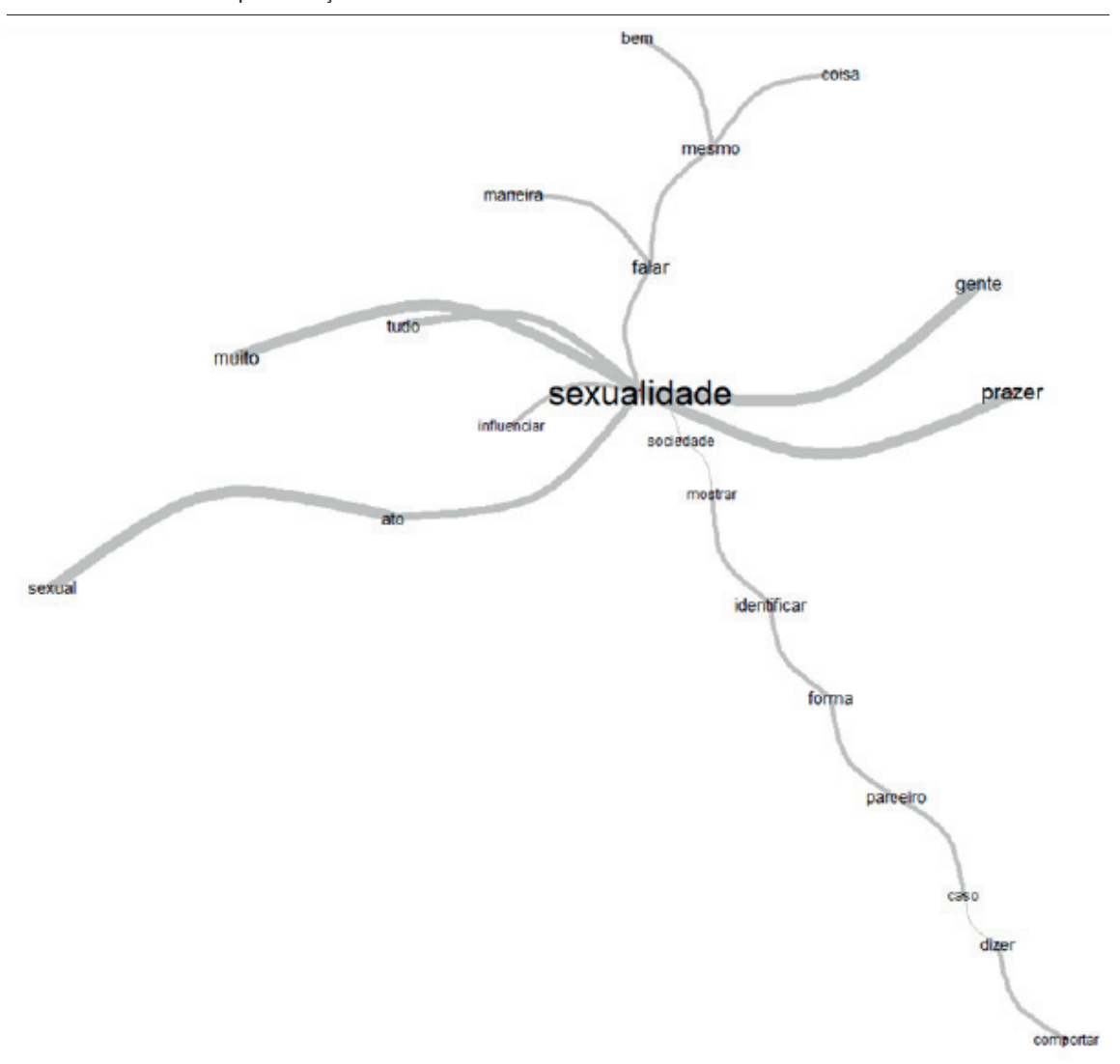


Com base na imagem gerada pela Análise de Similitude, observa-se que as representações que os estudantes possuem sobre a sexualidade não estão relacionadas apenas ao ato sexual, mas abrangem outros fatores tais como atitudes que geram bem-estar no dia a dia, comportamentos e o prazer de forma geral. Sendo, portanto, esta a representação do conceito de sexualidade para estes discentes. Essa visão está presente nos diversos depoimentos dos participantes do GF2 e do GF3:

É aquilo que lhe dá prazer. Independente de ser relacionado a sexo ou não (GF2).

Para mim, sexualidade é uma lingerie que a gente coloca, uma calça que a gente veste, um vestido, um abraço que a gente dá, um beijo, uma dança, o ato sexual em si, muita coisa (GF3).

Dessa forma, a conceituação feita pelos discentes desses GFs atinge as diversas facetas da sexualidade e de como ela se constrói. Apresentaram um entendimento amplo do que é sexualidade, conceituando-a como diversas formas de prazer e ser, para além do ato sexual, tendo como foco da discussão a formação profissional e experiências vivenciadas.

No entanto, para o GFl, a representação da sexualidade limita-se à visão de si próprio, à interação com o outro e à parceria sexual. Ao falar sobre o conceito de sexualidade, o GFl se limitou à identidade, à aceitação de si mesmo e à interação com o outro. $\mathrm{O}$ foco da discussão foi a identidade sexual.

Identidade. Aceitação também (GFl).

É a forma como você se identifica, como você se sente daquela forma e também a questão dos parceiros. Como você se mostra para a sociedade (GF1).

Nesse sentido, é perceptível a disparidade de entendimento sobre o tema entre o GF1 e os GF2 e GF3.

Dias (2015), observou em sua pesquisa que os estudantes do último ano do curso de Enfermagem de uma universidade de Portugal demonstraram atitudes mais favoráveis ao tema sexualidade quando comparados aos estudantes do $1^{\circ}$ ano, salientando a influência do curso sobre a percepção do tema.

Evidencia-se, portanto, a relevância que a formação teve na construção das representações sobre sexualidade. Apesar da influência que algumas disciplinas têm na compreensão do discente sobre o tema, esteve presente nos discursos o sentimento de receio, timidez e despreparo ao lidar com a sexualidade do outro.

Tendo em vista que esses sentimentos representam barreiras durante a prática ou a vida profissional, é preciso reafirmar a necessidade de uma me- 
lhor abordagem da sexualidade durante a formação dos enfermeiros, com o objetivo de compreendê-la como parte da integralidade, propiciando melhores condições de vida para a sociedade (Tsai et al., 2014).

Considera-se, então, necessária a criação de espaços de discussão que produzam reflexões para o cuidado da sexualidade do paciente, bem como para os discentes, pois se acredita que, ao enxergarem sua própria sexualidade, passarão a compreender melhor a sexualidade do outro e assim romper os tabus em torno do tema (Sehnem, 2013a).

É notória a necessidade de disciplinas específicas para o estudo da sexualidade humana que compreendam não apenas o biológico, mas que ampliem o conhecimento sobre o tema em sua multiplicidade (Rezende e Sobral, 2015), que visem também os aspectos políticos e sociais.

\section{Considerações Finais}

O aprendizado dos discentes apresentou-se de forma semelhante em todos os grupos. Na escola e no âmbito familiar a sexualidade era um tema a ser evitado ou até mesmo reprimido, sendo realizado através de conversas e troca de experiências entre os amigos.

As representações dos estudantes de enfermagem sobre a sexualidade foram mais abrangentes para os discentes do $6^{\circ}$ e do $9^{\circ}$ períodos e se ancoram no entendimento de que, além do ato sexual e do comportamento, são todas atitudes que culminam em bem-estar, ao passo que, para os do $2^{\circ}$ período, as representações se ancoram em visão de si próprio, identidade e interação com o outro. Assim, a formação durante o curso contribuiu para a mudança; para os discentes, a religião e a timidez do paciente representam barreiras na abordagem da sexualidade. Os sentimentos expressados ao abordá-la sugerem que este tema ainda representa um tabu, sendo os principais a vergonha e a timidez. Outro sentimento que se mostrou presente em todos os grupos foi o de despreparo para a abordagem da sexualidade nas atividades práticas.

O trabalho contribuiu para a compreensão das representações sobre sexualidade dos estudantes de enfermagem e as lacunas existentes na formação, sendo fundamental que o tema seja mais trabalhado no meio acadêmico.

Partindo da compreensão de que, quanto maior o nível de conhecimento menos barreiras existem na abordagem à sexualidade, recomenda-se a existência de mais espaços de discussão no meio acadêmico e na sociedade, além de maiores investimentos no ensino que não se limite à teoria, mas que compreenda também a prática, por meio de grupos de pesquisa e extensão. 


\section{Colaboradores}

Trycia Ryane de Freitas Silva e Sabrina Emylle Torres Fernandes participaram de todas as etapas concepção, delineamento, execução da pesquisa, análise e interpretação dos dados e revisão crítica do artigo. Sheila Milena Pessoa dos Santos orientou o planejamento e a realização da pesquisa, bem como a revisão final do artigo. Andreza Josiany Aires de Farias, Nemório Rodrigues Alves e José Antonio da Silva Júnior trabalharam na redação e revisão crítica do conteúdo. Os autores declaram não haver conflito de interesses.

\section{Notas}

Artigo extraído do trabalho de conclusão de curso de graduação em enfermagem intitulado "Representações dos estudantes de Enfermagem sobre sexualidade", de autoria de Trycia Ryane Freitas da Silva, defendido em 2018. A pesquisa foi aprovada em Comitê de Ética em Pesquisa e não foi financiada.

\section{REPRESENTACIONES DE LOS ESTUDIANTES DE ENFERMERÍA SOBRE LA SEXUALIDAD: ENTRE ESTEREOTIPOS Y TABÚES}

Resumen Considerando la sexualidad como parte fundamental de la vida humana, este estudio buscó comprender la representación que tienen al respecto los estudiantes de enfermería. Se optó por un estudio con delineamiento cualitativo, basado en la teoría de las Representaciones Sociales. La población del estudio se compuso por estudiantes de la carrera de grado de una institución pública. La recolección de datos se realizó por medio de la técnica de grupo focal, orientada por un guión. El análisis se realizó con la ayuda del IRaMuTeQ versión 0.7 alpha 2 y se basó en el Análisis de Contenido. La sexualidad se representa como un tema a mantener oculto en el ámbito familiar y escolar. Más allá que la formación se manifiesta como un factor que contribuye en el cambio de la concepción sobre la sexualidad, durante las prácticas de los estudiantes se hicieron presentes sentimientos como vergüenza y timidez, constatando que sus representaciones se aferran a estereotipos y tabúes. En este sentido, es visible la necesidad de más espacios de discusión en el medio académico y la sociedad, de manera que no se limite sólo a la teoría, sino que comprenda también la práctica.

Palabras clave sexualidad; educación en enfermería; salud sexual; representaciones sociales. 


\section{Referências}

ALBUQUERQUE, Grayce A. et al. Saberes e práticas sexuais de adolescentes do sexo masculino: Impactos na saúde. Revista de Enfermagem do Centro-Oeste Mineiro, Minas Gerais, v. 4, n. 2, p. 1.146-1.160, maio/ago 2015. Disponível em: < http://www.seer.ufsj. edu.br/index.php/recom/article/view/588 >. Acesso em: 10 jul. 2017.

ALENCAR, Danielle L. et al. Fatores que interferem na sexualidade de idosos: uma revisão integrativa. Ciência \& Saúde Coletiva, Rio de Janeiro, v. 19, n. 8, p. 3.533-3.542, 2014.

BARDIN, Laurence. Análise de conteúdo. Lisboa: Edições 70, 2006.

BUSIN, Valéria M. Religião, sexualidades e gênero. REVER-Revista de Estudos da Religião, São Paulo, v. 11, n. 1, p. 105-124, 2011. Disponível em: < https://revistas.pucsp.br/ index.php/rever/article/view/6032>. Acesso em: 1 fev. 2018.

BERNARDES, Margarida M. R. et al. Análise iconográfica articulada. Revista Enfermagem $U E R J$, Rio de Janeiro, v. 22, n. 2, p. 18792, mar.- abr. 2014. Disponível em: <http:// www.facenf.uerj.br/v22n2/v22n2a07.pdf >. Acesso em: 14 abr. 2017.

CAMARGO, Brigido V.; JUSTO, Ana M. IRAMUTEQ: um software gratuito para análise de dados textuais. Temas em Psicologia, Ribeirão Preto, v. 21, n. 2, p. 513-518, dez. 2013. Disponível em: <http://pepsic.bvsalud.org/scielo. php?script=sci_arttext\&pid=S1413-389X201 $3000200016 \& \operatorname{lng}=$ pt\&nrm $=$ iso $>$. Acesso em: 14 jul. 2018.

CESNIK, Vanessa M. et al. The sexual life of women with breast cancer: meanings attributed to the diagnosis and its impact on sexuality. Estudos de Psicologia (Campinas), Campinas, v. 30, n. 2, p. 187-197, jun. 2013. Disponível em: <http://www.scielo.br/scielo. php?script $=$ sci_arttext $\&$ pid $=$ S0103-166X201 $3000200005 \& \operatorname{lng}=\mathrm{en} \& \mathrm{nrm}=\mathrm{iso}>$. Acesso em: 27 mar. 2017.
CHIAPINOTTO, Luciane; FAIT, Cláudia S.; MAYER JUNIOR, Manoel. O modo de fazer saúde: reflexões sobre o cotidiano de uma unidade básica de saúde de Porto Alegre - RS. Saúde e Sociedade, São Paulo, v. 16, n. 1, p. 155-164, abr. 2007. Disponível em: $<$ http://www.scielo.br/scielo.php?script=sci abstract\&pid=S0104-12902007000100014\&lng=e $\mathrm{n} \& \mathrm{nrm}=\mathrm{iso} \& \operatorname{tng}=\mathrm{pt}>$. Acesso em: 13 ago. 2017.

COSTA, Lúcia H. R.; COELHO, Edméia A. C. Ideologias de gênero e sexualidade: a interface entre a educação familiar e a formação profissional de enfermeiras. Texto \& Contexto Enfermagem, Florianópolis, v. 22, n. 2, 2013. Disponível em: $<$ http://www.scielo.br/pdf/tce/v22n2/v22n2a26. pdf $>$. Acesso em: 26 Jun. 2018.

COSTA, Lúcia H. R.; COELHO, Edméia A. C. Enfermagem e sexualidade: revisão integrativa de artigos publicados na Revista LatinoAmericana de Enfermagem e na Revista Brasileira de Enfermagem. Revista Latino-Americana de Enfermagem, Ribeirão Preto, v. 19, n. 3, p. 631-639, jun. 2011. Disponível em: <http://www.scielo.br/scielo.php?script=sci arttext\&pid=S0104-11692011000300024\&lng =en\&nrm=iso >. Acesso em: 19 fev. 2018.

CRESWELL, Jhon W. Projeto de pesquisa: método qualitativo, quantitativo e misto. 2. ed. Porto Alegre: Artmed, 2007.

DIAS, Hélia; SIM-SIM, Margarida. Representações sobre sexualidade dos estudantes do 1. ${ }^{\circ}$ ano do curso de enfermagem: um estudo exploratório. Revista da UIIPS, Santarém, Pará, v. 3, n. 5, p. 385-395, 2015. Disponível em: < http://ojs.ipsantarem.pt/index.php/REVUIIPS/ article/view/111>. Acesso em: 9 fev. 2018.

FERREIRA, Simone M. A. et al. Barreiras na inclusão da sexualidade no cuidado de enfermagem de mulheres com câncer ginecológico e mamário: perspectiva das profissionais. Revista Latino-Americana de Enfermagem, Ribeirão Preto, v. 23, n. 1, p. 82-89, fev. 2015. Disponível em: <http://www.scielo.br/pdf/rlae/ 
v23n1/pt_0104-1169-rlae-23-01-00082.pdf >. Acesso em: 27 mar. 2017.

GARCIA, Olga R. Z.; LISBOA, Laura C. S. Consulta de enfermagem em sexualidade: um instrumento para assistência de enfermagem à saúde da mulher, em nível de atenção primária. Texto \& Contexto Enfermagem, Florianópolis, Santa Catarina, v. 21, n. 3, 2012.

HEILBORN, Maria L. Entre as tramas da sexualidade brasileira. Revista Estudos Feministas, Florianópolis, v. 14, n. 1, p. 43-59, abr. 2006. Disponível em: <http://www.scielo.br/scielo. php?script $=$ sci_arttext $\&$ pid $=$ S0104-026X200 $6000100004 \& \operatorname{lng}=\mathrm{en} \& \mathrm{nrm}=\mathrm{iso}>$. Acesso em: 5 mar. 2017.

HORA, Dayse M.; SCHINDHELM, Virginia G. Chuveirinhos e torneirinhas. Gênero e sexualidade no currículo da educação infantil. Educação em Foco, v. 18, n. 25, p. 55-75, 2015. Disponível em: < http://revista.uemg.br/ index.php/educacaoemfoco/article/view/302>. Acesso em: 17 mar. 2017.

LOURO, Guacira L. Gênero, sexualidade e educação: das afinidades políticas às tensões teórico-metodológicas. Educação em Revista, Belo Horizonte, n. 46, p. 201-218, dez. 2007. Disponível em: <http://www.scielo.br/ scielo.php?script $=$ sci_arttext $\&$ pid $=$ S0102$46982007000200008 \& \operatorname{lng}=\mathrm{en} \& \mathrm{nrm}=\mathrm{iso}>$. Acesso em: 12 mar. 2017.

MORAES, Patrícia R. et al. Teoria das representações sociais. Revistas Eletrônicas UNISEPE, UNIFIA, São Paulo, 2013. Disponível em: < http://unifia.edu.br/revista_eletronica/revistas/ direito_foco/artigos/ano2013/teoria_representacoes.pdf >. Acesso em: 1 mar. 2017.

NOBREGA, Danielle O.; ANDRADE, Erika R. G.; MELO, Elda S. N. Pesquisa com grupo focal: contribuições ao estudo das representações sociais. Psicologia e Sociedade, Belo Horizonte, v. 28, n. 3, p. 433-441, dez. 2016. Disponível em: <http://www.scielo.br/scielo.php?script=sci_ arttext\&pid=S0102-71822016000300433\&lng $=\mathrm{en} \& \mathrm{nrm}=\mathrm{iso}>$. Acesso em: 7 mar. 2017.
PANCAKE, Rachel M. Sex shame and pleasure. 2012. 107f. Tese (Doutorado em Ciencias)California State University, Northridge, 2012. Disponível em: <http://scholarworks.csun. edu/handle/10211.2/2784>. Acesso em: 12 fev. 2018.

QUEIRÓS, Pollyanna S. et al. Concepções de pais de adolescentes escolares sobre a sexualidade de seus filhos. Revista RENE: Revista da Rede de Enfermagem do Nordeste, Fortaleza, CE, v. 17, n. 2, 2016. Disponível em: <http:// www.periodicos.ufc.br/index.php/rene/article/ view/3043/2346 >. Acesso em: 17 mar. 2017

RESSEL, Lúcia B. Vivenciando a sexualidade na assistência de enfermagem: um estudo na perspectiva cultural. 2003. $334 \mathrm{f}$. Tese (Doutorado em Enfermagem) - Universidade de São Paulo, São Paulo, 2003. Disponível em: <http:// www.teses.usp.br/teses/disponiveis/83/83131/ tde-28102004-102256/en.php>. Acesso em: 19 fev. 2018

REZENDE, Anyelle V.; SOBRAL, Osvaldo J. O estudo da sexualidade na formação superior do profissional de enfermagem. IV Semana de Integração: XIII Semana de Letras, XV Semana de Pedagogia e I Simpósio de Pesquisa e Extensão (SIMPEX) - Educação e Linguagem: (re)significando o conhecimento. 2015. Disponível em: <http://www.anais.ueg.br/index. php/semintegracao/article/view/5570/3353>. Acesso em: 21 mar. 2017.

SAUNAMÄKI, Nina; ENGSTRÖM, Maria. Registered nurses' reflections on discussing sexuality with patients: responsibilities, doubts and fears. Journal of Clinical Nursing, [s.1.], v. 23, n. 3-4, p. 531-540, 2014. Disponível em: <https://onlinelibrary.wiley. com/doi/full/10.1111/jocn.12155>. Acesso em: 19 fev. 2018.

SEHNEM, Graciela D. et al. A construção da sexualidade de estudantes de enfermagem e suas percepções acerca da temática. Ciencia y Enfermería, Concepción, v. 20, n. 1, p. 111121, abr. 2014. Disponível em: <https://scielo. conicyt.cl/scielo.php?script=sci_arttext\&pi $\mathrm{d}=$ S0717-95532014000100010 > . Acesso em: 24 mar. 2017. 
SEHNEM, Graciela D. et al. A sexualidade na formação acadêmica do enfermeiro. Escola Anna Nery Revista de Enfermagem, Rio de Janeiro, v. 17, n. 1, p. 90-96, mar. 2013a. Disponível em: <http://www.scielo. br/scielo.php?script=sci_arttext\&pid=S1414$81452013000100013 \& \operatorname{lng}=\mathrm{en} \& \mathrm{nrm}=\mathrm{iso}>$. Acesso em: 24 mar. 2017.

SEHNEM, Graciela D. et al. A sexualidade no cuidado de enfermagem: retirando véus/ The sexuality in nursing care: removing veils. Ciência, Cuidado e Saúde, Maringá, v. 12, n. 1, p. 72-79, 2013b. Disponível em: <http:// www.lume.ufrgs.br/handle/10183/115387>. Acesso em: 12 mar. 2017

SILVA, Lizele Q. P.; SCHMITZ, Nara H.; MENEZES, Marina. Perspectivas parentais sobre a sexualidade de crianças atendidas em clínica-escola de psicologia. Psicologia Argumento, Curitiba, v. 33, n. 81, 2017.

SILVEIRA, Gabriella F. et al. Produção científica da área da saúde sobre a sexualidade humana. Saúde e Sociedade, São Paulo, v. 23, n. 1, p. 302312, jan.-mar. 2014. Disponível em: <http:// www.scielo.br/scielo.php?script=sci_arttex t\&pid=S0104-12902014000100302> . Acesso em: 27 mar. 2017.
TRAD, Leny A. B. Grupos focais: conceitos, procedimentos e reflexões baseadas em experiências com o uso da técnica em pesquisas de saúde. Physis: Revista de Saúde Coletiva, Rio de Janeiro, v. 19, n. 3, p. 777-796, 2009. Disponível em: <http://www.scielosp.org/scielo.php?script=sci arttext\&pid=S0103-73312009000300013\&lng= en\&nrm=iso >. Acesso em: 7 mar. 2017.

TSAI, Li-Ya et al. Undergraduate nursing education to address patients' concerns about sexual health: the perceived learning needs of senior traditional four-year and two-year recurrent education (rn-bsn) undergraduate nursing students in Taiwan. Nagoya Journal of Medical Science, Nagoya, v. 76, n. 3-4, p. $273,2014$.

WORLD HEALTH ORGANIZATION. Sexual health [Internet]. Genebra: WHO; 2017. Disponível em: <http:/www.who.int/topics/ sexual_health/en/>. Acesso em: 19 mar. 2019.

ZILIOTTO, Gisela C.; MARCOLAN, João F. Percepção de trabalhadores de enfermagem sobre sexualidade de portadores de transtornos mentais. Acta Paulista de Enfermagem, São Paulo, v. 26, n. 1, p. 86-92, 2013. Disponível em: <http:// www.scielo.br/scielo.php?script=sci_arttex $\mathrm{t} \& \mathrm{pid}=\mathrm{S} 0103-21002013000100014>$. Acesso em: 20 mar. 2017. 